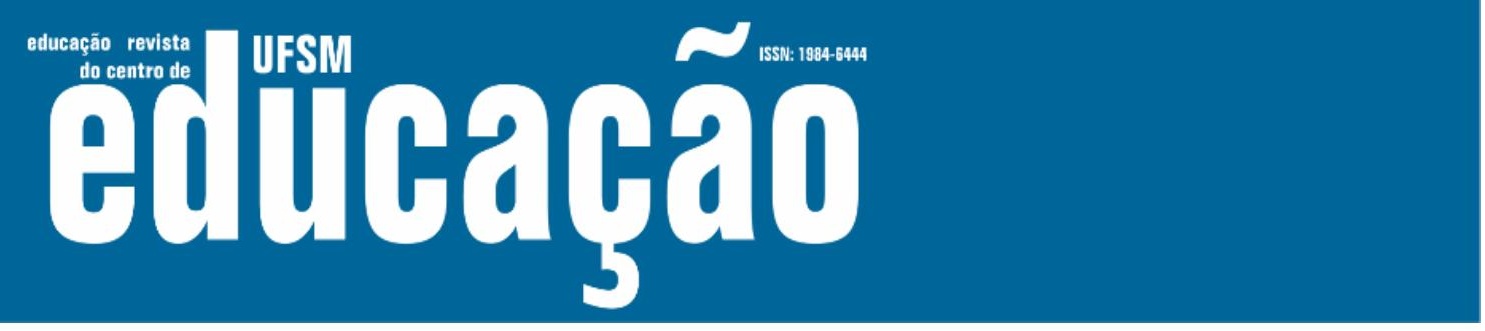

ISSN: 1984-6444 | http://dx.doi.org/10.5902/1984644444169

\title{
Narrativas na (e para a) formação de professores: algumas mobilizações no âmbito do Pibid-UFSCar
}

Narratives in (and for) teacher education: some mobilizations within Pibid - UFSCar

Ana Claudia Molina Zaqueu-Xavier

Professora Doutora na Universidade Federal de Uberlândia. Uberlândia, Minas Gerais, Brasil. ana.zaqueu@ufu.br - https://orcid.org/0000-0001-9057-4435

Recebido em 08 de maio de 2020

Aprovado em 20 de novembro de 2020

Publicado em 30 de junho de 2021

\section{RESUMO}

Apresentar e discutir alguns modos de mobilização de narrativas na (e para a) formação de professores no Programa Institucional de Bolsas de Iniciação à Docência (Pibid) da Universidade Federal de São Carlos, UFSCar, é o objetivo deste artigo. Para isso, nos respaldamos em narrativas - produzidas no âmbito de uma pesquisa de doutorado - de oito coordenadores de área de subprojetos e de dois excoordenadores institucionais do Pibid-UFSCar, bem como em documentos oficiais que versam sobre o programa desta instituição. Trata-se, portanto, de um trabalho qualitativo cujo movimento analítico foi inspirado no modelo de análise narrativa. Isto porque, optou-se por assumir as narrativas como foco do estudo, sobretudo, por defendermos que nossos interesses de pesquisa estavam pautados na subjetividade dos sujeitos e, nessa direção, as narrativas podem ser tomadas como espaços nos quais eles tecem sentidos, criam significados e se constituem nos diferentes espaços e tempos. A partir disso, apresentaremos uma versão possível para o Pibid-UFSCar bem como alguns modos de mobilização de narrativas na (e para a) formação docente, enfatizando o trabalho com portfólios por eles desenvolvidos. De modo geral, chamaremos atenção do leitor para algumas das potencialidades do trabalho narrativo percebidos nesse cenário como, por exemplo, a criação de um espaço menos verticalizado para discussões e problematizações de temas e ideias, a possibilidade de acompanhamento do processo de tornar-se professor, a contribuição para o desenvolvimento da Língua Portuguesa, da escrita, da oralidade, dentre outros aspectos.

Palavras-chave: Narrativas; Formação de professores; Pibid. 


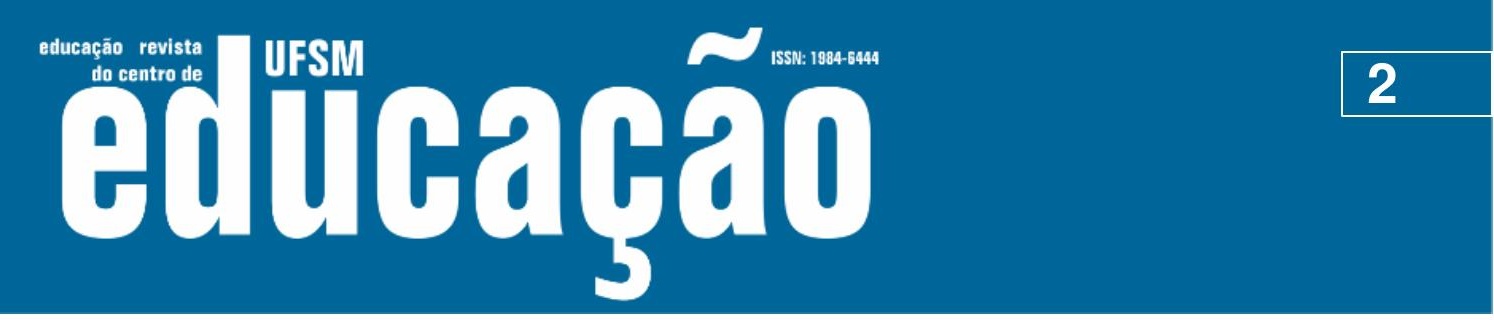

ISSN: 1984-6444 | http://dx.doi.org/10.5902/1984644444169

\section{ABSTRACT}

The objective of this article is to present and discuss some ways of mobilizing narratives in (and for) teacher training in the Institutional Program for Teaching Initiation Scholarships (Pibid) at the Federal University of São Carlos, UFSCar. To this end, we rely on narratives - produced as part of a doctoral research - of eight subproject area coordinators and two former institutional coordinators of Pibid-UFSCar, as well as official documents dealing with this institution's program. It is, therefore, a qualitative work whose analytical movement was inspired by the model of narrative analysis. This is because, we chose to assume the narratives as the focus of the study, above all, because we defend that our research interests were based on the subjectivity of the subjects and, in this direction, the narratives can be taken as spaces in which they weave meanings, create meanings and are constituted in different spaces and times. Based on that, we will present a possible version for Pibid-UFSCar as well as some ways of mobilizing narratives in (and for) teacher training, emphasizing the work with portfolios developed by them. In general, we will draw the reader's attention to some of the potentialities of narrative work perceived in this scenario, for example, the creation of a less vertical space for discussions and problematization of themes and ideas, the possibility of monitoring the process of becoming a teacher, the contribution to the development of the Portuguese language, writing, orality, among other aspects. Keywords: Narratives; Teachers training; Pibid.

\section{Introdução}

O estudo aqui apresentado encontra-se respaldado nos dados narrativos produzidos no interior de uma pesquisa de doutorado cujo cenário investigativo foi o Programa Institucional de Bolsas de Iniciação à Docência, Pibid, da Universidade Federal de São Carlos, UFSCar (ZAQUEU-XAVIER, 2019). Tais fontes são constituídas por documentos oficiais do Pibid desta instituição - Projeto Institucional e Regimento Interno - e de narrativas produzidas a partir de momentos de entrevistas com oito coordenadores de área de subprojetos e dois ex-coordenadores ${ }^{1}$ institucionais que haviam ocupado tais posições durante o período de vigência do edital analisado, a saber, edital de ํㅜ 061/2013.

Em relação a produção dos dados, cabe ressaltar que o Pibid-UFSCar se caracteriza por ser intercampi e, por isso, os dados dizem de mobilizações narrativas nos campi de Araras, São Carlos e Sorocaba. Além do mais, destaca-se que as 


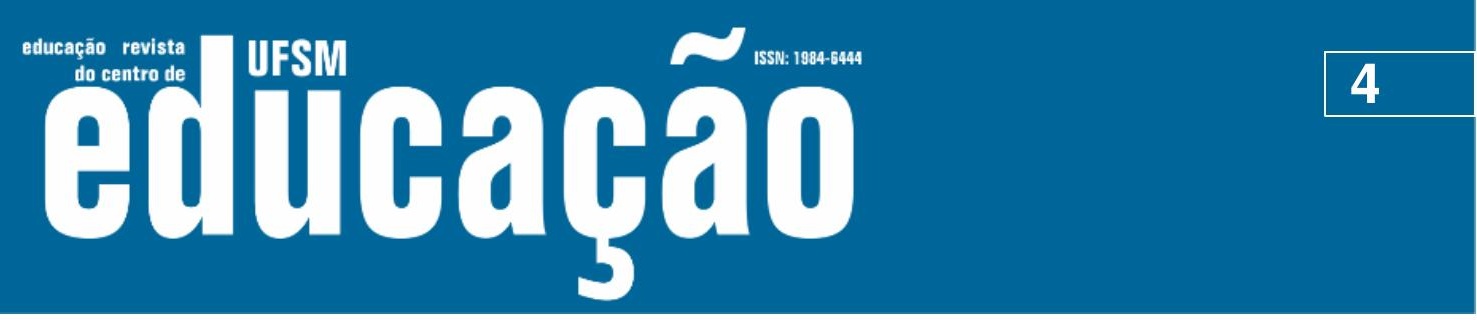

ISSN: 1984-6444 | http://dx.doi.org/10.5902/1984644444169

A precariedade da educação no Brasil é reconhecida também pelos organismos internacionais. O Relatório da Unicef de 2011 aponta como causas da enorme evasão escolar no país: (1) insuficiente número de escolas; (2) deficiente estrutura física das escolas; (3) falta de valorização dos professores (...); (4) ausência de formação adequada dos professores; (5) deficiente qualidade de ensino; (6) falta de acesso e meio de transporte para estudantes (...). O Relatório de 2016 (online) revela a tragédia de $38 \%$ de adolescentes em todo país estarem vivendo em situação de extrema pobreza. O dado representa um aumento de $29 \%$ em relação à média da população brasileira (GADELHA, 2017, p. 171).

Nesse contexto, as narrativas tendem a contribuir para que os sujeitos possam refletir sobre essas e outras questões que vão além dos muros da escola, rompendo com pressupostos de que o espaço escolar, a educação e as relações que perpassam a escola são impermeáveis aos fatores externos, isto é, aos efeitos da política, da economia e do meio sociocultural. Desse modo, entendemos que as formas narrativas, uma vez que podem ser vistas como meios pelos quais nos subjetivamos e compreendemos a nós mesmos e ao mundo que criamos, em uma época em que as singularidades, subjetividades, pluralidades e coletividade têm sofrido duras críticas em prol de um ensino/pensamento livre de ideologias (se é que é possível), elas têm se mostrado potentes para o desenvolvimento e discussão de temas sensíveis às realidades que envolvem o processo de formação de professores.

Além disso, entendemos que professores/ educadores estão interessados no processo de ensino-aprendizagem e em como ele se dá e, por isso, têm interesse em discutir e problematizar temas que os possibilitem "saber lidar com as vidas diferentes, os valores diferentes, as atitudes diferentes, as crenças, os sistemas sociais, as instituições e estruturas e no como eles estão unidos para aprender e ensinar" (CLANDININ; CONNELLY, 2015, p. 22). Nesse sentido, defendemos que as narrativas, quando mobilizadas na (e para a) formação de professores, têm a potência de criar espaços para que tais problematizações ocorram.

No que diz respeito à abordagem narrativa, esta inicia-se em contexto Europeu por volta dos anos de 1980. No Brasil, tal movimento passa a ser percebido nos anos de 1990, quando há uma intensificação em trabalhos que envolvem pesquisas biográficas e autobiográficas. Autores como Nóvoa (2000) defendem que a pesquisa com formas narrativas retrata uma necessidade em (re)pensar a produção de 


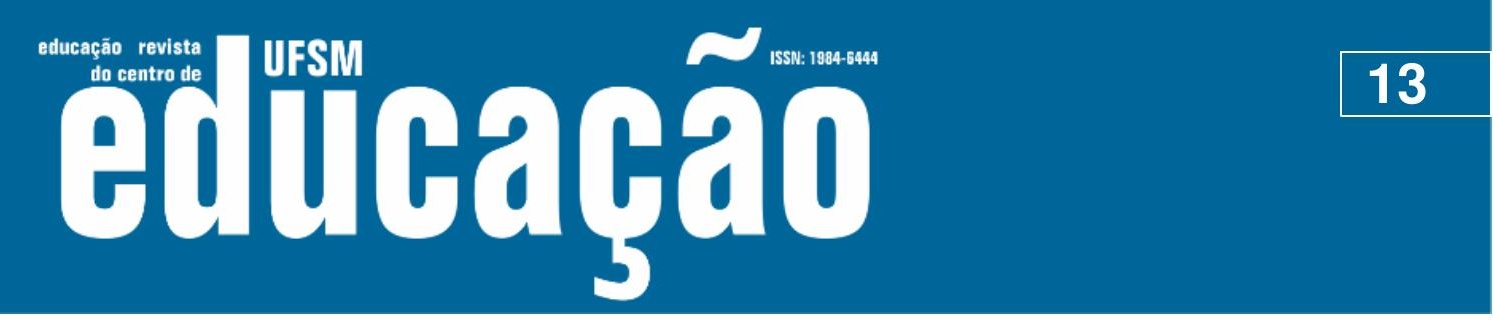

ISSN: 1984-6444 | http://dx.doi.org/10.5902/1984644444169

Além disso, essa configuração do Programa vem acompanhada por uma proposta de trabalho em torno das narrativas. Segundo o Projeto Institucional do PIBID-UFSCar, os licenciandos

[...] são convidados a, juntamente, com coordenadores das áreas e supervisores, escreverem e apresentarem em eventos acadêmicos: 1) atividades de ensino e/ou situações de aprendizagem; 2) projetos de ensino; 3) artigos; 4) relatos de experiências; 5) capítulos de livros; 6) relatórios científicos e 7) escritas reflexivas, no formato de portfólios (PROJETO INSTITUCIONAL, 2013, p. 4, destaque nosso).

Ainda, no que tange o Regimento Interno elaborado pela Comissão de Acompanhamento do Pibid-UFSCar, CAP, fica previsto, no capítulo III, que trata "Dos instrumentos de registro das atividades", em seu artigo de número 18, que

O desenvolvimento dos Subprojetos do Projeto Institucional será acompanhado pela CAP e pela Coordenação Institucional do Pibid- UFSCar, mediante instrumentos de registros das atividades, incluindo a obrigatoriedade de: I - diário de atividades; II - relatórios; III - portifólios (REGIMENTO INTERNO, 2014, p. 5, destaque nosso).

Pode-se notar que desde a elaboração do Projeto Institucional havia uma movimentação em torno do trabalho narrativo. Em entrevista concedida ao trabalho de Zaqueu-Xavier (2019), Maria do Carmo de Sousa, professora que coordenou institucionalmente o Pibid-UFSCar entre os anos de 2007 e 2015, afirmou que

\begin{abstract}
Nós, professores do DME e envolvidos com as disciplinas de estágio, entendíamos que uma forma do aluno começar a ter uma visão menos óbvia da escola, sem ser tão respaldada no senso comum, era se ele tivesse que escrever e pensar sobre a sua própria escrita. [...] Nossa ideia era uma escrita mais livre, de forma que pudessem narrar e, ao mesmo tempo, na medida do possível, ir teorizando sobre suas narrativas. Nós escolhemos os portfólios [...] A ideia não era somente que os alunos fizessem isso para compreender a escola. Nós, mesmos que implicitamente, colocamos essa escrita como uma forma avaliativa (ZAQUEU-XAVIER, 2019, p. 119-120).
\end{abstract}

Esse movimento, ao que tudo indica, foi ganhando espaço até o instante em que deixou de ser um convite e passou a ser uma obrigatoriedade no interior do PibidUFSCar, ampliando, inclusive, seus objetivos que eram, inicialmente, os de criar 




ISSN: 1984-6444 | http://dx.doi.org/10.5902/1984644444169

que articula "em diferentes contextos, tempos e interações, vários conhecimentos relativos ao saber ser, saber fazer e saber conduzir-se" (FREITAS, 2006, p. 276).

No que se segue, apresentaremos o trabalho com narrativas na (e para a) formação de professores no âmbito do Pibid-UFSCar, enfatizando as abordagens via portfólios.

\title{
Narrativas na (e para a) formação de professores: algumas possibilidades mobilizadas junto ao Pibid-UFSCar
}

A partir da caracterização do Pibid-UFSCar tecida anteriormente e da apresentação de algumas das formas narrativas mobilizadas pelos sujeitos que atuam no Programa desta instituição, destacamos o trabalho com os portfólios, diários e relatórios, sobretudo dos portfólios que, apesar de institucionalizados, podemos notar que a partir da análise das narrativas e documentos oficiais é que há uma pluralidade de compreensões e modos de mobilização que vão ao encontro das necessidades dos subprojetos, da área de atuação e dos referenciais teóricos que embasam as práticas dos docentes coordenadores, dentre outros aspectos.

Exemplo disso pode ser visto quando observamos o "convite" para mobilizar formas narrativas impressas no Projeto Institucional e a "obrigatoriedade" desses usos via Regimento Interno. Além disso, em relação à pluralidade de compreensões, por exemplo, a professora Heloisa Sisla afirma que o "portfólio é um instrumento importante para o pibidiano aprender a ser professor. É para isso que serve o texto do portfólio" (ZAQUEU-XAVIER, 2019, p. 42) e segue dizendo que

\begin{abstract}
A ideia do portfólio do pibidiano é a de que ele seja composto por vários textos que, por sua vez, sejam empregados no processo de ensino aprendizagem desses estudantes e como modo de acompanhar a evolução de seu aprendizado com sua participação no Pibid. Portanto, o caráter desse portfólio é reflexivo (ibid., p. 38, destaque nosso).
\end{abstract}

Ainda sobre isso, a fala da professora Elaine Furlan, coordenadora do Subprojeto Pibid Química-UFSCar/Araras, ressalta que 




ISSN: 1984-6444 | http://dx.doi.org/10.5902/1984644444169

[...] quando falo de narrativas, não estou dizendo somente da oralidade e da escrita. Estou falando de formas de expressão. [...] Nós trabalhamos muito com as manifestações culturais, como por exemplo, representar questões da Ciência ou da Docência por gravuras, pintura, música, poesia, teatro etc. que é quando eles elencam um tema de estudo e precisam desenvolver alguma atividade que esteja relacionada com uma questão cultural. [...] Essas outras manifestações, elas ocorrem, mas é um processo difícil. Os alunos demoram para perceber que isso também faz parte, então, quando ficamos neste meio mais formal, escrito e oral, é o que eles compreendem melhor (ZAQUEU-XAVIER, 2019, p. 176-177, destaque nosso).

Para o professor Estéfano, a narrativa conta "uma história, que é uma história de vida, contar uma história, você pode fazer isso através de uma fotografia, de um desenho, de um vídeo ou você pode escrever" (ZAQUEU-XAVIER, 2019, p. 104, destaque nosso), enquanto, para a professora Fernanda Silva, o "portfólio é importante tanto para o processo formativo dos meus alunos quanto como interesse de pesquisa" (ibid., p. 79, destaque nosso).

Por fim, ressaltamos a fala da professora Isadora Gregolim, coordenadora do Subprojeto Pibid-UFSCar/São Carlos, ao afirmar que, para ela,

[...] o portfólio tem duas funções. [...] a gente considera que o portfólio, ao mesmo tempo, é organizador, porque é uma materialidade escrita, que permite você acompanhar o processo, as reformulações, mas também revelador. O portfólio, portanto, não só organiza, mas também revela para si mesmo, para os licenciandos e para os orientadores e supervisores, os avanços, os movimentos (ZAQUEU-XAVIER, 2019, p. 112, destaque nosso).

Com isso, pode-se notar que, apesar da institucionalização, há uma pluralidade de compreensões do que sejam as narrativas bem como suas possibilidades. Isso também pode ser visto em relação às mobilizações o que, para nós, faz sentido uma vez que se têm diferentes linhas de entendimento. Sobre isso - pluralidade de mobilizações - recorremos à fala da professora Heloisa Sisla, ao afirmar que 




ISSN: 1984-6444 | http://dx.doi.org/10.5902/1984644444169

[...] as narrativas, aqui no Pibid da UFSCar, elas são, como na formação de professores em geral, escritas. Existe uma orientação geral, a todos os pibidianos, para que eles produzam textos semestrais e analíticos, sob a supervisão dos coordenadores. [...] Essa orientação que comentei, tem quatro passos [...] Portanto, nos portfólios tem a contextualização, uma parte descritiva, uma analítica e uma analítica de diálogo com referenciais teóricos. [...] ao longo desses anos em que venho corrigindo portfólios, fui cercando os problemas que eram recorrentes e construí um instrumento de devolutiva: uma tabela. [...] eu vejo essas questões de se entregou no prazo; se acatou as orientações; se eliminou os erros ortográficos; se realizou revisão para tornar a redação mais clara; se buscou concisão; se apresentou outras dificuldades na escrita; se incluiu trechos do diário; se tem diálogo com a literatura; qual a qualidade e a quantidade de referências, isso porque vinha gente com portfólio com uma ou duas referências. [...] se cumpriram com as normas descritas pela Associação Brasileira de Normas Técnicas, ABNT; se fez citação e referência de acordo com a ABNT. Isso é uma coisa que a gente tem que cuidar. Tanto do português quanto da escrita acadêmica (ZAQUEU-XAVIER, 2019, p. 35, destaque nosso).

E da professora Clelia Mara, coordenadora do Subprojeto Pibid Química UFSCAR/São Carlos, ao afirmar que seu

[...] objetivo com esses portfólios é tanto formativo quanto avaliativo, certo? Ele é tudo isso. Nós queremos que os alunos adquiram o hábito de escrever, de registrar suas ideias, de descrever o que fez e ir refletindo sobre o que faz e sobre o que pretende fazer. Tudo o que é pensado deve ser colocado no portfólio. Isso é parte fundamental da formação. Agora, quando eu digo "avaliação", claro que o portfólio não é um instrumento que vai decidir se um aluno fica ou não no Pibid. Fazer ou não um bom portfólio, não é critério de avaliação, mas ele ajuda a verificar onde estão as dificuldades do aluno (ZAQUEU-XAVIER, 2019, p. 150, destaque nosso).

Assim, constatamos que, por mais que existem diferenças, muitas vezes sutis, entre uma forma de compreensão, de mobilização e outra, é possível identificar um pano de fundo que tangencia grande parte das ações com narrativas. Ou seja, percebemos um consenso de que a ação de escrever sobre as vivências e refletir sobre elas são de fundamental importância para o desenvolvimento pessoal e profissional, e que o uso desse tipo de estratégia tende a contribuir para processos de formação, avaliação e aperfeiçoamento e domínio da Língua Portuguesa, promovendo a capacidade comunicativa do licenciando que é algo que todos os docentes, independente da área de atuação, devem contribuir. 




ISSN: 1984-6444 | http://dx.doi.org/10.5902/1984644444169

Apesar dos documentos oficiais não explicitarem as bases que fundamentam o trabalho com portfólios no Pibid-UFSCar, as entrevistas das professoras Clelia Mara, Maria do Carmo e Isadora Gregolin revelam um embasamento teórico nos trabalhos de Villas Boas (2004) que, por sua vez, entende que a escrita perpassa os princípios de construção, reflexão, criatividade, parceria, autoavaliação e autonomia. Ou seja, para essa autora, as narrativas, em especial os portfólios de que ela trata, englobam os princípios de construção, criatividade e autonomia, uma vez que são os alunos quem elaboram, sistematizam, escolhem e criam seu material segundo suas intenções e, além disso, perpassam os princípios de reflexão, autoavaliação e parceria, na medida em que os alunos pensam sobre os porquês dos episódios selecionados, comparam e analisam o progresso de seus trabalhos e, estabelecem um diálogo com seus formadores.

Nessa direção, a professora Isadora afirma em sua narrativa que o modo como conduzem o trabalho narrativo no Pibid-UFSCar, em especial no subprojeto que coordena, contribui para que o aluno desenvolva sua criticidade e exemplifica essa situação ao afirmar que

\begin{abstract}
Recentemente, tivemos e ainda está tendo, uma discussão sobre a Base Nacional Comum Curricular, BNCC, e nós tivemos vários bolsistas que trouxeram para os portfólios, visões críticas sobre a própria existência dessa Base Nacional e de como, naquele contexto em que eles estavam inseridos, isso poderia interferir de uma forma negativa. Então, eles já vão se posicionando criticamente enquanto professores e vão saindo de uma posição de alunos de licenciatura e incorporando em seus textos, esses movimentos mais críticos em direção a uma concepção mais transformadora da realidade (ZAQUEU-XAVIER, 2019, p. 110-111, destaque nosso).
\end{abstract}

Com isso, percebemos que o trabalho narrativo apresenta ou dá indícios de um imperativo sobre a reflexão. Assim, destacamos que nosso entendimento sobre o movimento reflexivo é o de que ele tende a ser um processo em que o sujeito reflete "sistematicamente sobre o modo pelo qual suas práticas podem fomentar as aprendizagens de seus alunos, tanto para compreender melhor como isso pode ocorrer, como também para redirecionar suas ações pedagógicas" (REALI; REYES, 2009, p.12). 


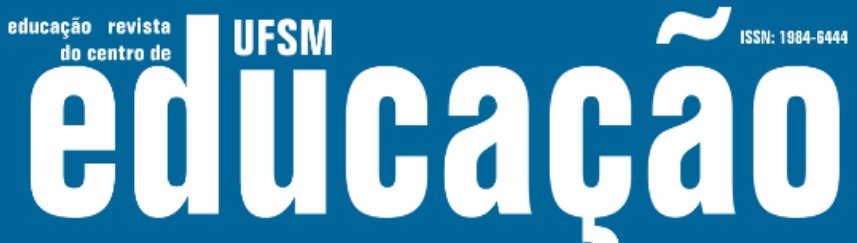

ISSN: 1984-6444 | http://dx.doi.org/10.5902/1984644444169

almejada, segundo a autora, no Pibid-UFSCar. Nessa última visão, a escola é tida como produtora de conhecimento, como instituição capaz de promover transformações sociais e há uma valorização da reflexão e abandono do princípio da neutralidade.

Ao mobilizar as narrativas na (e para a) formação de professores, em especial os portfólios, entende-se que espaços outros são gerados para a discussão e problematização de temas e conteúdos que perpassam a formação de todos os envolvidos. O que se percebe é um processo em que a coletividade e a pluralidade de ideias, valores, crenças, ideologias, saberes e verdades são tão valorizadas quanto às subjetividades e singularidades, constatação essa que vai ao encontro das preocupações que surgiram a partir dos anos 2000 e que mudaram o foco das investigações sobre formação de professores de questões sobre "como formar o professor?", para "como nos tornamos educadores(as)?", ou seja, há um destaque para a temática de construção das identidades múltiplas dos docentes.

O trabalho narrativo, quando acompanhado, orientado e problematizado tende a criar um espaço de produção e formação de docentes e pesquisadores que supera uma ideia de universalidade abstrata em prol da pluriversalidade que, por sua vez, reflete um modo de agir e pensar que promove uma descolonização do sujeito e valoriza as diferenças, características essas, presentes nas epistemologias de Sul de que trata Santos (2019).

\section{Considerações finais}

Nossa intenção ao elaborar este artigo foi o de apresentar e discutir a mobilização de narrativas na (e para a) formação de professores a partir de um estudo que tomou como cenário investigativo o Pibid-UFSCar. Para isso, focamos nossa discussão sobre o que, para os envolvidos no Programa desta instituição, há de potente ao trabalhar com instrumentos narrativos, em especial, o portfólio.

De modo geral, no âmbito do Pibid-UFSCar, há uma pluralidade de formas e objetivos almejados ao mobilizar estes instrumentos. As intenções que mais se sobressaem são a formação e a avaliação, sendo está última, tomada no sentido de 




ISSN: 1984-6444 | http://dx.doi.org/10.5902/1984644444169

acompanhamento de processos. Cabe ressaltarmos que, ao falarmos em potencialidades, estamos nos referindo ao que está em estado de potência, ou seja, tanto no que tange aspectos positivos quanto negativos.

Desse modo, devemos ter em mente que, ao trabalharmos com instrumentos narrativos, é grande o número de resultados "positivos" para a formação, entretanto, não podemos nos esquecer das responsabilidades e dificuldades que surgem em meio a esse movimento como, por exemplo, deixar claro ao estudante que existem diferentes formas de se trabalhar a formação sem a limitação da oralidade ou escrita.

Se tomarmos como referência um dos propósito das Epistemologias do Sul, ou seja, a de que "temos que transformar o mundo ao mesmo tempo que permanentemente o reinterpretamos; tanto quanto a própria transformação, a reinterpretação do mundo é uma tarefa coletiva" (SANTOS, 2019, p. 9), o trabalho narrativo que aqui apresentamos, mostra-se como uma estratégia possível para que possamos entrar nesse movimento e (re)conduzir nossas práticas no que diz respeito não só a formação de professores como a Educação de modo geral.

\section{Referências}

ABREU, Ana Sílvia Couto de. Leitura e escrita enquanto práticas discursivas: construindo filiações. Revista Iberoamericana de Educación, Espanha, v. 2, n. 48, p. 1-7, jan. 1997.

ARAGÃO, Ana Lúcia Assunção; NAVARRO, Almira. Diálogos em Diálogo: David Bohm, Paulo Freire e Mikhail Bakhtin. Educação em Questão, Rio Grande do Norte, v. 19, n. 5, p. 108-118, jan./abr. 2004.

ASSOCIAÇÃO NACIONAL DE PÓS-GRADUAÇÃO E PESQUISA EM EDUCAÇÃO. A política de formação de professores no Brasil de 2018: uma análise dos editais capes de residência pedagógica e Pibid e a reafirmação da resolução CNE/CP 02/2015. Audiência do Conselho Nacional de Educação em 09 de abril de 2018, 2018.

BAMBERG, Michael. Narrative Analysis. In: COOPER, Harris. (Ed.). APA Handbook of Research Methods in Psychology. Washington, DC: APA Press, 2012. p. 77-94.

BRASIL. Lei de Diretrizes e Bases da Educação Nacional. Lei número 9394, 20 de dezembro de 1996. 


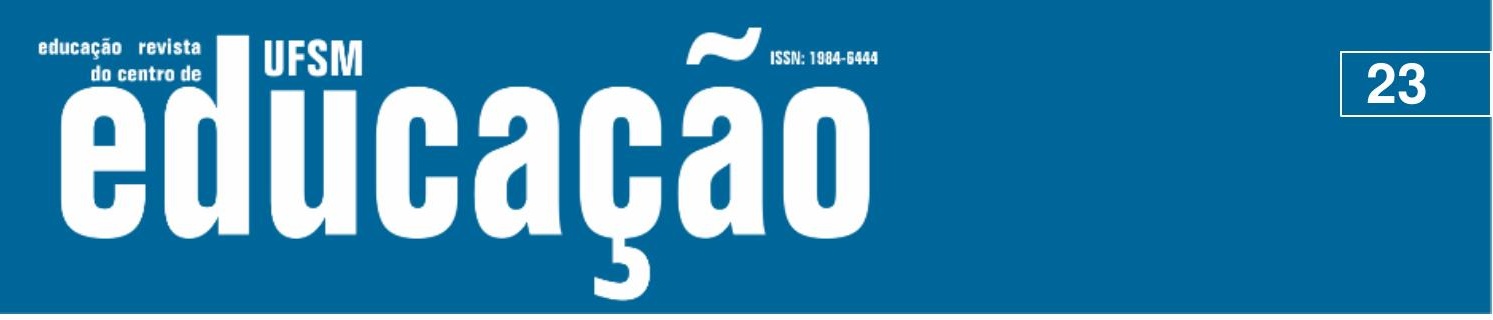

ISSN: 1984-6444 | http://dx.doi.org/10.5902/1984644444169

MOUTINHO, Karina; CONTI, Luciana de. Análise Narrativa, Construção de Sentidos e Identidade. Psicologia: Teoria e Pesquisa, Brasília, v. 32, n. 2, p. 1 - 8, 2012.

NACARATO, Adair Mendes; PASSOS, Cármen Lucia Brancaglion; SILVA, Heloisa da. Narrativas na pesquisa em Educação Matemática: caleidoscópio teórico e metodológico. Bolema, Rio Claro, v. 28, n. 49, p. 701 - 716, ago. 2014.

NÓVOA, António. Vidas de professores. 2. ed. Porto: Porto Editora, 2000.

PORTARIA NORMATIVA № 38, DE 12 DE DEZEMBRO DE 2007. Dispõe sobre o Programa de Bolsa Institucional de Iniciação à Docência - PIBID. Diário Oficial da República Federativa do Brasil. Brasília, DF. 2007b.

REALI; Aline Maria de. Medeiros Rodrigues; REYES, Claudia Raimundo. Reflexões sobre o fazer docente. São Carlos: EdUFSCar, 2009. 96 p.

RUIZ, Antonio Ibanez; RAMOS, Mozart Neves; HINGEL, Murílio. Escassez de Professores no Ensino Médio: propostas estruturais e emergenciais. Brasília: Ministério da Educação/ Conselho Nacional de Educação/ Câmara de Educação Básica, 2007. 36 p.

SÁ-CHAVES, Idália. Portfolios Reflexivos. Estratégia de formação e de Supervisão. 3. ed. Aveiro: Unidade de Investigação Didáctica e tecnologia na Formação de Formadores, 2004. 60 p.

SANTOS, Boaventura de Sousa. O fim do Império Cognitivo: a afirmação das epistemologias do Sul. Belo Horizonte: Autêntica Editora, 2019.

SOUSA, Maria do Carmo de. Práticas Interdisciplinares e Parceria Compartilhada no PIBID-UFSCar: perspectivas e desafios. In: BOZZINI, I. C. T. et al. (Org.). Pibid UFSCar: uma parceria colaborativa entre universidade e escola. São Carlos: Pedro \& João Editores, 2018, p. 55-74.

SOUSA, Maria do Carmo de. Formação docente nas licenciaturas da UFSCar: contribuições do Pibid. Espaço Plural, Marechal Cândido Rondom, n. 26, p. 55-69, jan./ abr. 2012.

TIZZO, Vinícius Sanches. Mobilizações de Narrativas na (e para a) Formação de Professores: potencialidades no (e a partir do) Programa Institucional de Bolsas de Iniciação à Docência. 2019. 488 f. Tese (Doutorado em Educação Matemática) Universidade Estadual Paulista "Júlio de Mesquita Filho", Instituto de Geociências e Ciências Exatas, Rio Claro, 2019.

UNIVERSIDADE FEDERAL DE SÃO CARLOS. Projeto Institucional do Pibid UFSCar. São Carlos: UFSCar, 2013. 52 p. 


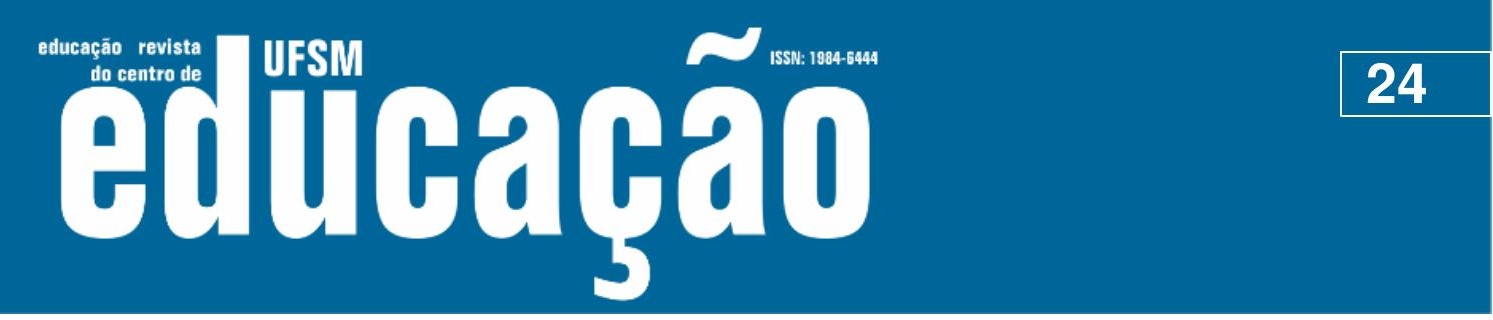

ISSN: 1984-6444 | http://dx.doi.org/10.5902/1984644444169 UNIVERSIDADE FEDERAL DE SÃO CARLOS. Regimento Interno do Pibid
UFSCar. São Carlos: UFSCar, 2014.11 p.

VILLAS BOAS, Benigna Maria de Freitas. Portfólio, avaliação e trabalho pedagógico. Campinas: Papirus, 2004.

ZAQUEU-XAVIER, Ana Claudia Molina. Narrativas na Formação de Professores: possibilidades junto ao Pibid da UFSCar. 2019. 304 f. Tese (Doutorado em Educação Matemática) - Universidade Estadual Paulista "Júlio de Mesquita Filho", Instituto de Geociências e Ciências Exatas, Rio Claro, 2019.

ZEICHNER, Kenneth M. Repensando as conexões entre a formação na universidade e as experiências de campo na formação de professores em faculdades e universidades. Educação Matemática, Santa Maria, v. 35, n. 3, p. 479-504, set./dez. 2010.

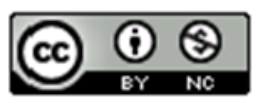

This work is licensed under a Creative Commons Attribution-NonCommercial 4.0 International (CC BY-NC 4.0)

\section{Notas}

\footnotetext{
${ }^{1}$ Ressaltamos que as cartas de cessão de direito das entrevistas bem como a concordância para que fossem mantidos os nomes dos colaboradores encontram-se disponíveis, em forma de anexo, no trabalho de Zaqueu-Xavier (2019).

${ }^{2}$ Ressaltamos que o senso comum é fundamental no processo de formação até porque, reflete uma construção histórico-cultural, entretanto, defendemos a necessidade de que, sob as devidas orientações e vivências teórico-práticas, os sujeitos possam superar tais formulações ou embasá-las de forma consistente.
}

${ }^{3}$ Sobre isso, destacamos que, as textualizações produzidas a partir dos momentos de entrevistas bem como as cartas de cessão de direitos encontram-se disponíveis, na íntegra, no trabalho de ZaqueuXavier (2019) e, por isso, as referências aos trechos de entrevista que, eventualmente, iremos apresentar, estarão vinculados a este trabalho.

${ }^{4}$ Esses três conceitos são apresentados e discutidos por Cortella (1997). Para esse autor, a visão otimista ingênua é otimista, por valorizar a escola, mas é ingênua, por desconsiderar as relações sociais que a atravessam; a pessimista ingênua, é pessimista por só levar em conta as exclusões e discriminações que a escola pode promover e é ingênua, por não perceber que ela é permeável aos conflitos e mudanças; por fim, a visão otimista crítica é otimista, por valorizar a escola e o papel do docente e é crítica, porque pressupõe movimentos reflexivos. 